\title{
El Marqués de Santillana y la Corona de Aragón en el marco del Humanismo peninsular
}

\author{
Miguel Ángel Pérez Priego
}

(UNED)

El Marqués de Santillana es seguramente uno de los más significativos y originales representantes del Humanismo peninsular hispánico. Por un lado, porque es uno de aquellos nobles letrados, quizá el principal, que tratan de armonizar armas y letras, saber y caballerfa, como asegura en su famosa sentencia al frente de los Proverbios: «la sçiencia non embota el fierro del espada nin faze floxa el espada en la mano del cavallero». Por otro, porque despliega a lo largo de su vida una afanosa actividad de busca y lectura de obras de la antiguiedad clásica, afán que culmina con la formación de una importantísima biblioteca en su palacio de Guadalajara y la creación de un nutrido grupo de intelectuales en torno a aquel ámbito cultural ${ }^{l}$. En tercer lugar, porque es un poeta extraordinariamente inquieto, que busca formas y perfección, y cree en el valor cívico de la poesía, como la define en el Prohemio e carta con acentos boccaccianos («un zelo çeleste, una afección divina, un insaçiable çibo del ánimas) y como lleva a la práctica en algunos poemas, entre los que citaría los Proverbios, dirigido al príncipe Don Enrique, que es una auténtica inducción al saber desde el lenguaje proverbial y la alusión culta, y el Bías contra Fortuna, destinado a su primo, el conde de Alba, en prisión, en el que recrea el mundo pagano de la filosofía estoica.

1 En el palacio de Guadalajara, don ffrigo formo una importantfsima biblioteca, poblada de cuidados manuscritos miniados y omamentados con su escudo de armas, en los que se recogfa lo más selecto y avanzado del saber de la epoca. Alli se encontraban, como muestra de la moderna inquietud humanística, clásicos griegos y latinos y modernos autores italianos, junto a los que pervivfan obras representativas del pensamiento religioso medieval, de la historiografia o del arte militar. All mantenía un auténtico círculo literario, compuesto por doctores y maestros en ciencias y letras, asI como traductores, copistas y artistas que trabajaban en su rica biblioteca. Para esta hizo traer de Italia las mejores versiones de los clásicos latinos e italianos, muchas de las cuales mandó traducir a la lengua castellana. En esas tareas colaboraron el capellán Pero Diaz de Toledo, los bachilleres Antón de Zorita, Juan de Salcedo y Alonso de Zamora, su secretario Diego de Burgos, o su escudero Martín de Ayala. Frecuentaban su bibliotoca y circulo literario, Juan de Mena, Juan de Lucena o Gómez Manrique. Inquietudes literarias compartió con el Alonso de Cartagena, obispo de Burgos, que le puso en relación con humanistas italianos, asl como el cordobes Nuño de Guzmán, también mecenas y bibliómano, y un tiempo residente en Florencia. 
Pues bien, gran parte de la formación y de la actividad cultural y literaria del Marqués de Santillana, está relacionada con la Corona de Aragón, con sus mandatarios y con sus escritores. Analizar estas relaciones contribuirá seguramente a entender mejor aquel rico mundo cultural.

Desde muy joven, cuando inicia su formación cortesana y caballeresca, don f́nigo López de Mendoza estuvo vinculado a la Corona de Aragón, en cuyas tierras residio bastante tiempo con viajes intermitentes a Castilla. A los quince años, en 1413, era ya copero de Alfonso V, todavía infante. En 1414, como recuerda la Crónica de Juan $\mathrm{II}^{2}$ acompaño, junto con otros nobles castellanos, a don Fernando de Antequera en su coronación como rey de Aragón. De las fiestas que alli se celebraron da cuenta en su crónica Alvar García de Santamaría, quien describe con detalle la ceremonia de su coronación, durante la cual, en el palacio de la Alfajería, tras el banquete, tuvo lugar una espectacular representación alegorica de Pecados y Virtudes, que se ha querido atribuir a don Enrique de Villena.

Desde entonces su relación con los príncipes e infantes de Aragón, hijos de don Fernando, fue intensa y sometida a los avatares de la veleidosa política nobiliaria de la época. Quiere decirse que unas veces se alineó al lado de los infantes frente al rey de Castilla y a su privado don Álvaro de Luna, como ocurrió en la década de los veinte, y otras, debilitados los infantes, sirvio a Juan II y hasta defendió la frontera de Castilla con Aragón y combatio a los infantes en la batalla de Olmedo.

Fundamental en sus aspiraciones humanísticas fue su encuentro con el mencionado don Enrique de Villena, precisamente en tierras de la Corona de Aragón. Donde por entonces residía con frecuencia don Enrique, que era primo del rey entronizado. Villena dedicaría a don finigo el interesantísimo Arte de trovar (conservado fragmentariamente), donde daba cuenta del intento de restaurar don Fernando el Consistorio de la Gaya Ciencia que había existido en Tolosa. Y también le dedicaría la traducción de la Divina Comedia y, en segunda instancia, después de iniciarla para Juan de Navarra, la Eneida de Virgilio, esto es, los dos libros seguramente más leídos y aprovechados por don Iñigo. Éste, a la muerte de Villena, compondría un solemne y sentido poema, una especie de planto cósmico de toda la creación por la pérdida de sabio tan excelso e impar.

El ejemplo de Villena hubo de ser decisivo para Santillana. Villena fue el animador cultural de aquella sociedad de nobles letrados, fue quien tradujo más y quien defendió más la idea de la necesidad del saber. En sus posesiones de Torralba o de Iniesta, hubo de reunir una importante biblioteca, en la que había

2 Estando el Rey en Zaragoza, mandó aparejar todas las cosas que eran necesarias para su coronación, en la qual vinieron muchos grandes Sefiores, así prelados como caballeros (...) Los notables Caballeros que de Castilla vinieron son éstos (...) Ifrigo López de Mendoza, señor de Hita y de Buitrago (...) $Y$ hecha la coronación con grandes alegrias e muchos menestriles de diversos instrumentos, las fiestas duraron diez dias... Y en estos días siempre hubo justas a dos tablas, en que se hicieron muy señalados encuentros* (Crónica de Juan II, af́o 1414, BEA, 68, pp. 358-360). 
obras de la antiguiedad clásica (sabemos que Alfonso $\mathrm{V}$ le pide copia de la historia de Trogo Pompeyo) y otras relacionadas con saberes y ciencias ocultas. Esa biblioteca fue quemada por Fray Lope Barrientos siguiendo órdenes de Juan II (que seguramente odiaba a Villena desde que éste apoyo a otros nobles en Tordesillas). El rey ordenó quemar los libros de ciencia prohibida y parece que Barrientos destruy6 cincuenta «de males artes» y otros quedaron en su poder. No se sabe qué suerte corrieron, pero alguno pasó a Santillana, que desde luego siguió el ejemplo bibliofílico de Villena. Juan de Mena lloraría en el Laberinto la pérdida de los libros de don Enrique:

¡O ínclito sabio, autor muy ciente,

otra e otra vegada yo lloro

porque Castilla perdio tal thesoro

non conoscido delante la gente!

Perdio los tus libros sin ser conoscidos,

e cómo en esequias te fueron ya luego

unos metidos al ávido fuego,

otros sin orden bien repartidos (...)

(cs. 127-128)

Santillana tuvo un conocimiento amplio de los poetas del Reino de Aragón, como expone en su famoso Prohemio e carta al condestable don Pedro de Portugal, donde por vez primera se hacía una breve historia de la literatura en las distintas lenguas románicas:

Los catalanes, valençianos e aun algunos del reino de Aragón fueron e son grandes ofiçiales desta arte [de la poesía] (...) Uvo entre ellos señalados onbres, as ́ en las invençiones como en el metrificar: Guillén de Berguedá, generoso e noble cavallero, e Pao de Benbibre adquirieron entr'estos grand fama. Mosén Pero March, el Viejo, valiente e honorable cavallero, fizo asaz gentiles cosas e, entre las otras, escrivió proverbios de grand moralidad. En nuestros tiempos floresçió mosén Jorde de Sant Jorde (...) Mosén Febrer fizo obras nobles, e algunos afirman aya traído el Dante de lengua florentina en catalán, non menguando punto en la orden del metrificar e consonar. Mosén Ausiás March, el qual aún bive, es grand trobador e omne de asaz elevado espíritu.

Dentro de ese marco y aun en la concisión de sus palabras, el juicio sobre Ausias March parece muy certero y ajustado. Para Santillana, que lo conoce en vida, March era un gran trovador de muy elevado espíritu. Esos dos rasgos, gran poeta y espíritu elevado, definen muy certeramente la personalidad de March, por alguien que seguramente bien lo había conocido.

Porque, en efecto, Ausias March y el Marqués de Santillana son dos vidas y personalidades que corren paralelas en dos reinos peninsulares distintos a lo largo de la primera mitad del siglo XV. Son rigurosamente coetáneos y nacen (en 1397 March, y en 1398 Santillana) y mueren prácticamente el mismo año (San- 
tillana en 1458, March en 1459). A ambos les unió una común preocupación por la poesía y una común inquietud por el saber humanístico. Pero también les unió el común servicio caballeresco al rey Alfonso V de Aragón. A su corte marchó joven Santillana, alli velo sus primeras armas y en ella sirvio como copero al Magnánimo. March acompaño en sus primeras campañas italianas a Alfonso, combatio junto a él y le sirví como halconero mayor.

Uno y otro cantaron asimismo al Rey en su poesfa. Santillana, desde la distancia del reino de Castilla, cantó su derrota en Ponza frente a los genoveses como un golpe justo de fortuna ante los que consideraba peligros de la expansión aragonesa («Ca d'otra menra los unos serían / monarcas del mundo e grandes señores, / e otros languiendo de fambre morrían»), aunque le auguraba al tiempo un cercano porvenir de glorias y nuevas conquistas. Alcanzadas éstas con la toma definitiva de Nápoles en 1443, se lamentaría en un soneto de que las hazañas de Alfonso no hubieran sido debidamente cantadas por cronistas ni poetas:

Calla la pluma, e luze la espada

en vuestra mano, Rey muy virtuoso;

vuestra exçellençia non es memorada

e Calíope fuelga e a reposo.

Yo plango e lloro non ser comendada

vuestra eminençia e nombre famoso,

e redarguyo la mente pesada

de los bivientes, non poco enojoso,

porquen non cantan los veestros loores

e fortaleza de memoria digna

a quien se humillan los grandes señores,

a quien la Italia sobervia se inclina.

Dexen el carro los emperadores

a la vuestra virtud quasi divina.

Ausias March, por su parte, ya anciano y, como dice, alejado de los deleites del cuerpo, cantará los amores del Rey con la bella y joven napolitana Lucrezia d'Alagno. Amores que habían sido muy notorios y cantados por numeroso poetas $^{3}$. Para Ausias March, aunque en un poema oscuro y lleno de claves enigmáticas, aquel amor es una magnífica realización del amor perfecto que le ha obse-

${ }^{3}$ LOS amores de Alfonso con esta joven dama, en los últimos affos de su reinado en Nápoles y lejos de su esposa dofta Maria, fueron proverbiales. El rey, que la conoció a los cincuenta y un antos, se rindió incondicionalmente a su juventud y belleza. Como puro y leal enamorado cortes, para ella (y su familia) tuvo todas las atenciones y dádivas, a ella se sometió apasionadamente con un enamoramiento, según todos los testimonios, idealizado y casto. Prácticamente todos los poetas de la corte de Nápoles, en italiano, en 
sionado y atormentado en toda su obra, el amor que juntamente pone cuerpo y alma en juego («l'amor qu'ensemps met cos e arma $n$ jou»), que no renuncia a la carne ni al espíritu. Y Lucrezia, la amada, que merece de un rey su cautivada fe, es un ejemplo de todo bien, por lo que Dios ha permitido que Amor junte a ambos, una dos corazones en un querer. De este modo, March ha incorporado aquellos resonantes amores ajenos a su propia e íntima reflexión amorosa, al tema principal y obsesivo de su poesía.

Jordi de Sant Jordi es otro poeta catalán mencionado por Santillana: «En estos nuestros tienpos floresçió mosén Jorde de de Sant Jorde, cavallero prudente, el qual çiertamente conpuso asaz fermosas cosas, las quales él mesmo asonava ca fue músico exçellente; fizo entre otras una cançión de oppósitos que comiença "Tos jorns aprench e desaprench ensems". Fizo la Pasión de amor, en la qual copilo muchas buenas cançiones antiguas, asi destos que ya dixe como de otros». Lo conocí estando también al servicio de Alfonso V, como «cambrer» suyo, y por él sintió gran admiración y de él imitó el artificio poético de los opósitos («Lloro e río en un momento / e soy contento e quexoso, / ardid me fallo e medroso: / tales diformeças siento / por vos, dona valerosa»). Asimismo le dedico un gran poema celebrativo, un decir alegorico, en el que imagina su coronación. Narra un sueño del poeta que contempla la deslumbrante aparición de Venus con su cortejo de doncellas, ante quienes llegan Homero, Virgilio y Lucano acompañando al poeta Mossén Jordi, para el que piden la «corona / de los prudentes letrados», y que al punto le otorga la diosa. Hay allí motivos tomados de Dante, como la hora mitológica o el sueño con que se inicia la obra proceden en este caso de Dante, en tanto que el esquema general de la *coronación» seguramente lo toma de la Amorosa Visione de Boccaccio, en cuyo canto $\mathrm{V}$ se describe precisamente la coronación de Dante. Destaca en el poema el derroche omamental con que se describen, por ejemplo, la floresta de Venus, el cortejo de la diosa que irrumpe en escena sobre un engalanado elefante, $o$ el trono de rica pedreria:

De rubíes e diamantes

era la maçonería,

e de gruesa perlería

las lizeras çircunstantes,

esmeraldas relumbrantes

e çafires orientales

havía tantas e tales

que non bastan consonantes

(vv. 81-88)

latín, en catalán o en castellano, cantaron aquellos extracrdinarios amores del Rey, tratando de sublimarlos y justificarlos poeticamente. Unos desde la belleza y perfección de la dama, otros desde la fatalidad y designio inevitable del sentir amoroso, otros desde la ejemplaridad de un amor ideal y perfecto, otros, en fin, ensalzando la virtud de aquella relación derivada de la condición casi divina de la dignided real. 
En la corte catalano-aragonesa, cuyas principales ciudades recorrería, conoció Santillana a otros muchos personajes con los que luego mantendría trato literario o los celebraría en sus poemas. Así ocurrio con varias damas catalanas, aficionadas a las letras, y seguramente animadoras de la corte literaria.

A doña Juana de Urgel, condesa de Foix, dedicó - entre 1435, cuando casó con don Joan, comte de Foix, y 1444, cuando contrajo segundas nupcias con Joan Ramon Folch, comte de Cardona, un discreto poema de loores en el que exalta la belleza y condición de la fama:

Non punto se discordaron

el çielo e naturaleza,

señora, quando criaron

vuestra plaziente belleza;

quisieron e demostraron

su magnífica largueza,

segund vos proporçionaron

e ornaron de gentileza (...)

A doña Violante de Prades, condesa de Módica y Cabrera, admiradora de su poesía, enviaría, desde Guadalajara al palacio de los condes, por mediación de su servidor Palomar, un selecto cancionero de sus obras con una breve reflexión teórica sobre la poesía. Este pequeño cancionero lo compilaría hacia 1443-1444 y en él le ofrece las grandes novedades poeticas que por esos años están llevando a cabo: la compleja alegoría de la Comedieta de Ponça, los sentenciosos Proverbios y un grupo de Sonetos «que agora nuevamente he començado a fazer al itálico modo». Al frente de todo, una breve Carta en prosa, donde explica el título de comedieta, y hace una breve exposición de los tres estilos retóricos (comedia, tragedia, sátira):

Tituléla deste nonbre por quanto los poetas fallaron tres maneras de nonbres a aquellas cosas de que fablaron, es a saber: tragedia, sátira e comedia. Tragedia es aquella que contiene en sí caídas de grandes reys e príncipes (...) Sátira es aquella manera de fablar que tobo un poeta que se llamó Sátiro, el qual reprehendió muy mucho los viçios e lool las virtudes (...) Comedia es dicha aquella cuyos comienzos son trabajosos e tristes, e después el medio e fin de sus días alegre, gozoso e bien aventurado. E d'ésta usó Terençio Peno e Dante en el su libro, donde primeramente dize aver visto las dolores e penas infernales, e después el purgatorio, e alegre e bien aventuradamente después el paraíso.

En un sentido planto, entre fúnebre y amoroso, lloraría, como supo identificar Martín de Riquer, a la reina Margarita de Prades, muerta en 1430, siendo abadesa de Bonrepós de Monsant. Casada en 1409 con Martín el Humano y enviudada pocos meses después, la bella y joven reina, a quien don frnigo López habría conocido durante su estancia en Aragón, fue celebrada por numerosos poetas catalanes y castellanos, como Luys Ycart, Arnau March, Arnau d'Erill, 
Pedro de Santa Fe y, sobre todos, Jordi de Sant Jordi, que le dirigí apasionados versos. El Planto de la reina doña Margarida ofrece una curiosa fusión artística del relato amoroso con el lamento fúnebre, como convenía a tan celebrada y admirada señora. Tras la tópica descripción de la hora mitológica:

A la ora que Medea

su sçiençia prefería

a Jasón, quando quería

asayar la rica pera,

e quando de grado en grado

las tiniebras han robado

toda la claror febea (...),

el poeta asiste en sueños al duelo lastimero de Venus por la muerte de doña Margarida y al desfile de perosnajes ilustres convocados por la diosa que rinden homenaje a «la mejor de las mejores». De nuevo, el poema presenta un intenso uso de la alusión clásica y mitológica, sobre todo, en comparaciones y símiles para describir gestos y actitudes de los personajes, en clara función amplificativa y ornamental:

Qual la fija de Thoante

torno con el mensagero

su gesto de plazentero

en doloroso senblante (...),

atal, fuera de mi seso,

me levé como sandío,

sin fuerça, sin poderío,

bien como el çentauro Neso

del grand Hércules ferido

Con tal cara qual respuso

al marido Colatino

la romana que Tarquino

forçó, por do fue confuso,

me dixo triste llorando

(vv. 22-47)

Como vemos, el contacto con la Corona de Aragón es fundamental en la obra del Marqués de Santillana. Alli adquirió formación en años decisivos de aprendizaje. Conoció a figuras relevantes y a maestros, como don Enrique de Villena, que fueron decisivos en su trayectoria cultural. Estableció lazos políti- 
cos con los infantes de Aragón y con el Magnánimo. Conoció a poetas de elevada obra y espíritu, como Jordi de Sant Jordi y Ausias March. Tuvo trato con destacadas e influyentes damas de la corte, a las que dedicó sus versos. Curiosamente toda la poesía dedicada a estas personas está particularmente cuidada y repleta de alusiones cultas, como correspondería a un selecto auditorio con el que la referencia 'humanística' se buscase en clave de cierta complicidad cultural. 